
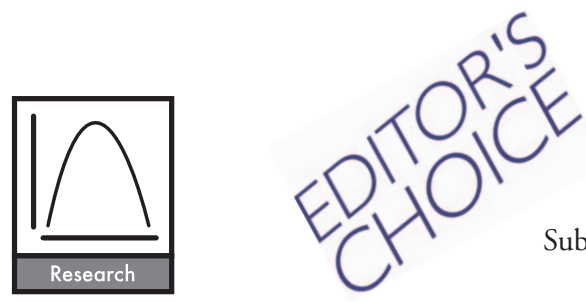

Ecography 38: 979-985, 2015

doi: $10.1111 /$ ecog.01348

(C) 2015 The Authors. Ecography (C) 2015 Nordic Society Oikos

Subject Editor: Thierry Oberdorff. Editor-in-Chief: Miguel Araújo. Accepted 6 January 2015

\title{
Non-native species modify the isotopic structure of freshwater fish communities across the globe
}

\author{
A. Sagouis, J. Cucherousset, S. Villéger, F. Santoul and S. Boulêtreau
}

A. Sagouis and J. Cucherousset (julien.cucherousset@univ-tlse3.fr), CNRS, Univ. Toulouse III Paul Sabatier, ENFA; UMR5174 EDB (Laboratoire Evolution et Diversité Biologique), 118 route de Narbonne, FR-31062 Toulouse, France. - S. Villéger, CNRS, Biodiversité Marine et ses usages (UMR MARBEC), Univ. de Montpellier, Place Eugéne Bataillon, FR-34095 Montpellier, France. - F. Santoul and S. Boulêtreau, Univ. de Toulouse, UPS, INP, EcoLab (Laboratoire Ecologie Fonctionnelle et Environnement), 118, route de Narbonne, FR-31062 Toulouse, France, and CNRS, EcoLab, FR-31062 Toulouse, France.

\begin{abstract}
Multiple anthropogenic pressures including the widespread introductions of non-native species threaten biodiversity and ecosystem functioning notably by modifying the trophic structure of communities. Here, we provided a global evaluation of the impacts of non-native species on the isotopic structure $\left(\delta^{13} \mathrm{C}\right.$ and $\left.\delta^{15} \mathrm{~N}\right)$ of freshwater fish communities. We gathered the stable isotope values $(n=4030)$ of fish species in 496 fish communities in lentic (lakes, backwaters, reservoirs) and lotic (running waters such as streams, rivers) ecosystems throughout the world and quantified the isotopic structure of communities. Overall, we found that communities containing non-native species had a different isotopic structure than communities without non-native species. However, these differences varied between ecosystem types and the trophic positions of non-native species. In lotic ecosystems, communities containing non-native species had a larger total isotopic niche than communities without non-native species. This was primarily driven by the addition of non-native predators at the top of the food chain that increased $\delta^{15} \mathrm{~N}$ range without modifying the isotopic niche size of native species. In lentic ecosystems, non-native primary consumers increased $\delta^{15} \mathrm{~N}$ range and this was likely driven by an increase of resource availability for species at higher trophic levels, increasing food chain length. The introduction of non-native secondary consumers at the centre of the isotopic niche of recipient communities decreased the core isotopic niche size, the $\delta^{13} \mathrm{C}$ range of recipient communities and the total isotopic niche of coexisting native species. These results suggested a modified contribution of the basal resources consumed (e.g. multi-chain omnivory) and an increase level of competition with native species. Our results notably imply that, by affecting the isotopic structure of freshwater fish communities at a global scale, non-native species represent an important source of perturbations that should be accounted for when investigating macro-ecological patterns of community structure and biotic interactions.
\end{abstract}

The importance of biodiversity in supporting ecosystem functioning and stability is now well recognized (Cardinale et al. 2006, Duffy et al. 2007, Thompson et al. 2012). Among the multiple facets of biodiversity, interactions between species (e.g. competition, predation, parasitism) are a major factor driving ecosystem functioning (Thompson et al. 2012). In particular, these interactions shape the architecture of food webs, i.e. the networks of trophic interactions that occur among species within ecosystems (Rooney and McCann 2012), which affects energy transfer across trophic levels and biogeochemical cycles within and across ecosystems.

Although food webs are assumed to provide a quantitative framework to link biodiversity and ecosystem functioning (Rooney and McCann 2012, Thompson et al. 2012), it is still unclear how changes in community composition could affect their trophic structure. This is especially true in the context of human-induced impacts such as the introduction of non-native species that have impacted biodiversity and ecosystem functioning. Indeed, introduced species modify community composition and the network of trophic interactions (through the extinction or extirpation of native species and the addition of new non-native species, Cucherousset et al. 2012b).

Freshwater ecosystems are considered among the most altered in the world, especially because of the widespread introduction of non-native fishes (Copp et al. 2005). Introduced fish species have been demonstrated to alter existing biological interactions among native species (Vander-Zanden et al. 1999, Cucherousset and Olden 2011). In many instances introduced fish species have a larger body size than native species (Blanchet et al. 2010) and large-bodied introduced predators could increase food chain length whereas largebodied introduced herbivores could modify the basal structure of food webs modifying the overall trophic structure of recipient communities (Cucherousset et al. 2012a). To date, however, most of the studies investigating the impacts of non-native species on the trophic structure of communities were conducted locally and there is to date no global understanding. This is despite the fact that such 
investigation could provide both applied and theoretical perspectives in our understanding of biological invasions and their effects on communities and food webs. Therefore it is urgent to investigate the ecological effects of non-native species on the trophic structure of communities at a global scale.

The burgeoning application of stable isotopes in ecology (Fry 2006) has provided new insights into trophic ecology by allowing a two-dimensional quantitative analysis of the horizontal (i.e. within a trophic level; $\delta^{13} \mathrm{C}$ ) and the vertical (i.e. along the food chain; $\delta^{15} \mathrm{~N}$ ) dimensions of food webs (Duffy et al. 2007). Predictable relationship between the stable isotope values of a consumer and its diet allow the study of trophic networks among species and the architecture of food webs (Fry 2006). In addition, recently developed multivariate metrics allow a quantitative assessment of the isotopic structure of communities (Layman et al. 2007, Jackson et al. 2011). Stable isotope consequently appeared as a powerful tool for investigating the consequences of nonnative fish species introductions on trophic structures (Vander-Zanden et al. 1999, Cucherousset et al. 2012b). Although there have been many studies using stable isotope analyses during the last two decades, global syntheses of this information to provide a broader macroecological understanding of the two-dimensional structure of food webs is limited (but see for instance Vander-Zanden and Fetzer (2007) for food chain length).

Here, we provide a global evaluation of the consequences of non-native species on the isotopic structure $\left(\delta^{13} \mathrm{C}\right.$ and $\delta^{15} \mathrm{~N}$ ) of freshwater fish communities. First, we test whether non-native species have modified the relationship between species richness and stable isotope niche size. We hypothesise that isotopic niche size of communities would increase with species richness differentially between communities with and without non-native species. Specifically, we predict that species richness will mechanically increase isotopic niche size through species addition and that, since non-native species differ from native species (Blanchet et al. 2010, Cucherousset et al. 2012a) and might use novel isotopic space in recipient communities, isotopic niche size will increase faster in communities with non-native species than in communities without non-native species. Second, we test whether the trophic position of non-native fish species is a consistent predictor of their effect on the isotopic structure of communities and we hypothesise that species with different trophic positions have different impacts on the trophic structure of recipient communities. Specifically, we predict that nonnative species with high trophic position will lengthen food chain through the addition mechanism (Post and Takimoto 2007) and will modify the isotopic niche of native species (Walsworth et al. 2013). We also predict that the insertion of non-native species with intermediate trophic position will lengthen food chain and diversify the spectrum of basal resources used in a community, contracting the isotopic niche of native species through competition. Finally, we predict that the introduction of species with low trophic position will increase the level of omnivory in the community, decreasing food chain length without modifying the isotopic niche of native species. These predictions were tested independently in lotic (flowing water) and lentic (standing water) ecosystems as they have been reported to differ regarding their trophic structure (Vander-Zanden and Fetzer 2007).

\section{Material and methods}

A total of 163 independent published studies (journal articles, university theses and reports, Supplementary material Appendix 1) about stable isotope values of freshwater fishes were collected using online search engines (ISIWeb of Knowledge ${ }^{\circledR}$ and Google Scholar ${ }^{\text {TM }}$ ) until 1 April 2013. All these publications provided raw isotopic values $\left(\delta^{13} \mathrm{C}\right.$ and $\left.\delta^{15} \mathrm{~N}\right)$ for at least four freshwater fish species in comprehensively sampled communities, which allowed computing relevant isotopic indices (see next section). In each source, stable isotope values were extracted from tables or figures for each fish community studied. When $\delta^{13} \mathrm{C}$ and $\delta^{15} \mathrm{~N}$ values were provided for different age classes or sub-species, they were averaged to obtain a single value per species. The final database contained a total of $4030 \delta^{13} \mathrm{C}$ and $\delta^{15} \mathrm{~N}$ values relative to 847 fish species present in 496 freshwater fish communities located in a total of 38 countries (Fig. 1). Among them, 305 were sampled in lentic ecosystems (i.e. lakes, reservoirs, backwaters) and 191 in lotic ecosystems (i.e. rivers, streams, brooks). All ecosystems were assigned to a drainage basin based on HydroSHED $15 \mathrm{~s}$ basin delineations (Lehner et al. 2006).

Information about species status (i.e. native or nonnative in each community), and trophic position of nonnative species was collected for each taxon in each community. Species status was defined at the country scale and obtained from FishBase (Froese and Pauly 2013), except in the USA where species status was defined at the state level using the USGS Nonindigenous Aquatic Species database $(<$ http://nas.er.usgs.gov $>)$. Trophic position values were collected for 769 species using FishBase (Froese and Pauly 2013) and the R package 'rfishbase' (Boettiger et al. 2012). According to their trophic position (TP), species were grouped into three trophic guilds: primary consumers $(\mathrm{TP} \leq 2.5)$, secondary consumers $(2.5<\mathrm{TP} \leq 3.5)$ and top predators $(\mathrm{TP}>3.5)$.

\section{Stable isotope metrics}

In each community, species richness was estimated as the total number of fish species that were analysed for stable isotopes. Because we selected articles that comprehensively sampled fish communities and that analysed at least four species in each community without explicitly stating that some species sampled where not analysed for stable isotopes, this provided a representative estimate of the local species richness interacting trophically. Since baselines (i.e. primary consumer stable isotope values) were not available for all the communities, raw stable isotope values of each freshwater fish species were transformed according to the community centroid, i.e. the average stable isotope values of all native and non-native species in a given community (following Schmidt et al. 2011). These standardized stable isotope values then allowed crosscommunity comparisons. Four isotopic metrics were computed for each fish community. First, two one-dimensional 


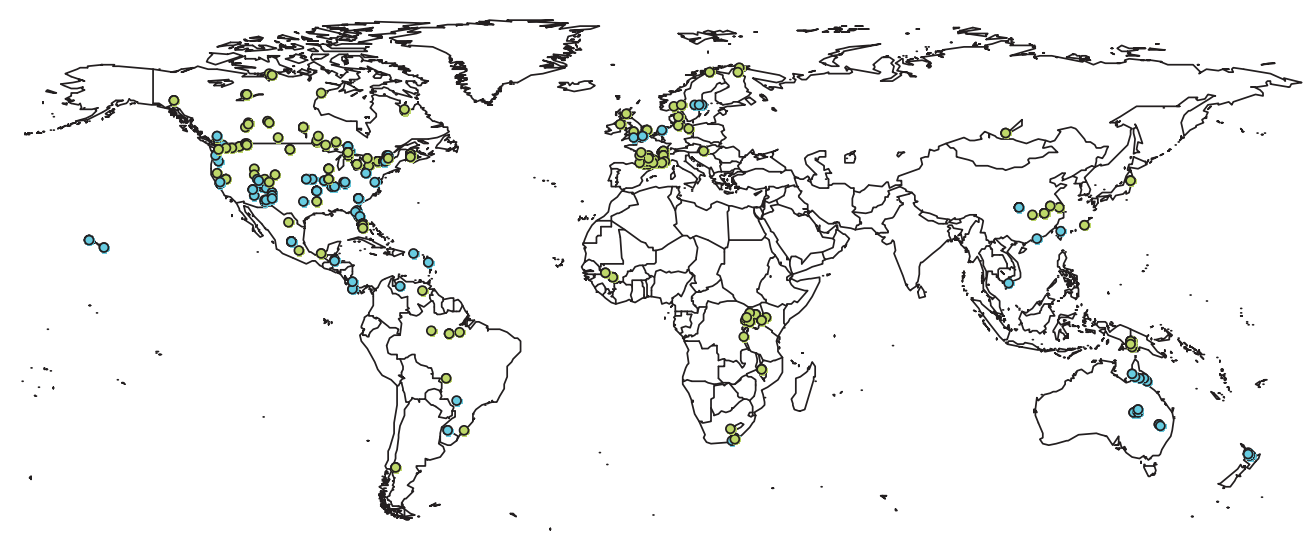

Figure 1. Geographical distribution of the freshwater fish communities in lentic (green dots) and lotic (blue dots) ecosystems with stable isotopes $\left(\delta^{13} \mathrm{C}\right.$ and $\left.\delta^{15} \mathrm{~N}\right)$ values.

metrics (' $\delta{ }^{13} \mathrm{C}$ range' and ' $\delta{ }^{15} \mathrm{~N}$ range') were calculated as the differences between maximal and minimal values for $\delta^{13} \mathrm{C}$ and $\delta^{15} \mathrm{~N}$ in a given community, respectively (Layman et al. 2007). Ecologically, $\delta^{13} \mathrm{C}$ range (horizontal dimension) represents the broadness of resources used in a community, and $\delta^{15} \mathrm{~N}$ range (vertical dimension) is an indicator of the number of trophic levels (i.e. food chain length) within a community. Second, the 'total isotopic niche' was quantified as the area within the convex hull shaping the community in the two-dimensional $\delta^{13} \mathrm{C}-\delta^{15} \mathrm{~N}$ space (Layman et al. 2007). This index was calculated for the entire community and for native species only (i.e. by excluding non-native species from the calculation in communities with non-native species). Third, the 'core isotopic niche' was calculated as the standard ellipse area (SEA), a two-dimensional metric that is less sensitive to extreme values than the total isotopic niche (Jackson et al. 2011). SEAc was used here to account for small sample number and computed based on Bayesian statistics (Jackson et al. 2011). These two last metrics provide complementary information about the isotopic niche of a community, with the convex hull area being driven by species located at the edges of the community while SEAc focuses of the centre of the stable isotope niche.

\section{Statistical analyses}

Lotic and lentic ecosystems displayed different isotopic diversity patterns (see details in Supplementary material Appendix 2) and the two ecosystem types were therefore analysed separately. To test our first hypothesis, the effects of the presence of non-native species on the relation between species richness and the total isotopic niche were tested using mixed effect models. The same analysis was performed for the core isotopic niche. These two metrics were selected here because they are a two-dimensional representation of all species in a community within the isotopic space. These models were first run with a pairwise interaction term (i.e. taxonomic richness $X$ non-native species presence) in addition to the explanatory variables. The interaction term was subsequently removed when not significant (Crawley 2012). To test our second hypothesis, the effects of non-native species on the horizontal and the vertical dimensions of the isotopic niche (i.e. $\delta^{13} \mathrm{C}$ and $\delta^{15} \mathrm{~N}$ ranges of the entire community) and on the total isotopic niche of native species (to fully account for the species located at the edges of the isotopic niche) were analysed by decomposing species richness (number of species in a community) in trophic guilds (sum of native and non-native species belonging to each trophic guild based on their trophic position) using a multiple regression approach (isotopic metric $\sim$ number of native primary consumers + number of non-native primary consumers + number of native secondary consumers + number of non-native secondary consumers + number of native top predators + number of non-native top predators + random effects). Isotopic metrics, except SEAc ellipses, were transformed using log function or Box-Cox transformation to meet normality assumptions. All hypotheses were tested with linear mixed effect models using study and location as random factors nested into drainage basin, since in many cases, more than one community were reported from the same study or from the same basin. Mixed effect models were computed using nlme package in $\mathrm{R}$ (Pinheiro et al. 2013, R Core Team).

\section{Results}

Irrespective of the presence of non-native species, total isotopic niche size significantly increased with increasing species richness (Fig. 2a, b). In lotic ecosystems, communities containing non-native species had a higher total isotopic niche than communities without non-native species $(p=0.026$; Table 1; Fig. 2a). However, no significant difference in the core isotopic niche was observed in lotic ecosystems ( $p=0.249$; Table 1 ; Fig. $2 c)$. In lentic ecosystems, the interaction term between non-native species presence and species richness had a significant effect on total isotopic niche $(\mathrm{p}<0.001$; Table 1; Fig. 2b). Total isotopic niche size increased at a slower rate with species richness in communities containing non-native species than in communities without nonnative species. A significant effect of the interaction term between non-native species presence and species richness was also observed for the core isotopic niche $(p=0.004$; Table 1). Core isotopic niche size increased with species 

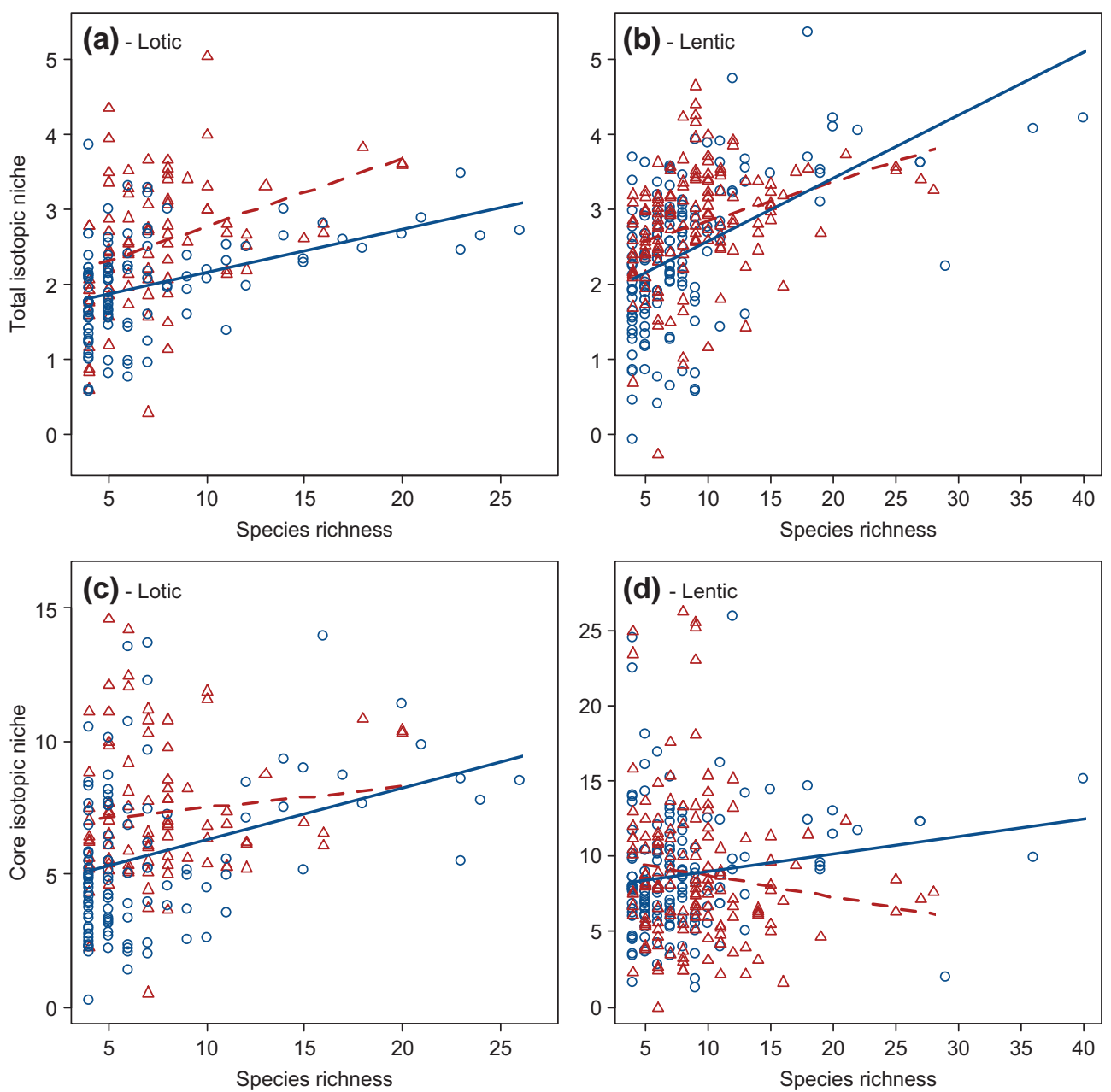

Figure 2. Relationship between species richness and total isotopic niche (first row, residuals) or core isotopic niche (second row, residuals) in communities with (red triangles) and without (blue circles) non-native species in lotic (a, c) and lentic (b, d) ecosystems. Continuous and dashed lines represent the regression lines in ecosystems without and with non-native species, respectively.

richness in communities without non-native species while it decreased with species richness in communities containing non-native species (Fig. 2d).

In lotic ecosystems, none of the trophic guilds significantly affected $\delta^{13} \mathrm{C}$ range (Table 2 and Supplementary material Appendix 3). $\delta^{15} \mathrm{~N}$ range significantly increased with the number of native $(\mathrm{p}=0.024$; Table 2$)$ and non-native $(p=0.036$; Table 2$)$ top predators while the other trophic levels had no significant effects on $\delta^{15} \mathrm{~N}$ range. The total isotopic niche size of native species significantly increased

Table 1. Effects of non-native species presence on total isotopic niche and core isotopic niche in lotic and lentic ecosystems tested using mixed effect models. Significant p-values $(\alpha=0.05)$ are displayed in bold.

\begin{tabular}{|c|c|c|c|c|c|c|}
\hline Ecosystem & Variable & Parameters & Estimate \pm SE & DF & $\mathrm{t}$-value & $p$-value \\
\hline \multirow[t]{6}{*}{ Lotic } & \multirow[t]{3}{*}{ Total isotopic niche } & Intercept & $0.38 \pm 0.18$ & 81 & 2.04 & 0.044 \\
\hline & & Species richness & $0.20 \pm 0.02$ & 64 & 12.00 & $<0.001$ \\
\hline & & Non-native presence & $0.36 \pm 0.16$ & 64 & 2.28 & 0.026 \\
\hline & \multirow{3}{*}{ Core isotopic niche } & Intercept & $4.13 \pm 0.77$ & 81 & 5.39 & $<0.001$ \\
\hline & & Species richness & $0.24 \pm 0.07$ & 64 & 3.30 & $<0.002$ \\
\hline & & Non-native presence & $0.80 \pm 0.79$ & 64 & 1.17 & 0.249 \\
\hline \multirow[t]{8}{*}{ Lentic } & \multirow[t]{4}{*}{ Total isotopic niche } & Intercept & $0.56 \pm 0.20$ & 126 & 2.80 & 0.006 \\
\hline & & Species richness & $0.24 \pm 0.02$ & 126 & 10.03 & $<0.001$ \\
\hline & & Non-native presence & $1.25 \pm 0.30$ & 126 & 4.19 & $<0.001$ \\
\hline & & $\begin{array}{l}\text { Species richness } \times \\
\quad \text { Non-native presence }\end{array}$ & $-0.12 \pm 0.03$ & 126 & -3.54 & $<0.001$ \\
\hline & \multirow[t]{4}{*}{ Core isotopic niche } & Intercept & $5.92 \pm 1.13$ & 126 & 5.22 & $<0.001$ \\
\hline & & Species richness & $0.33 \pm 0.13$ & 126 & 2.48 & 0.015 \\
\hline & & Non-native presence & $5.27 \pm 1.69$ & 126 & 3.12 & 0.002 \\
\hline & & $\begin{array}{l}\text { Species richness } \times \\
\text { Non-native presence }\end{array}$ & $-0.55 \pm 0.18$ & 126 & -2.97 & 0.004 \\
\hline
\end{tabular}


with the number of native top predators $(\mathrm{p}=0.032$; Table 2 ) but was not affected by the number of non-native species of each trophic guild ( $p>0.05$; Table 2 and Supplementary material Appendix 3). In lentic ecosystems, $\delta^{13} \mathrm{C}$ range significantly decreased with the number of non-native secondary consumers $(\mathrm{p}=0.005$; Table 2 and Supplementary material Appendix 3) and significantly increased with the number of non-native top predators $(p=0.015$; Table 2$)$. $\delta^{15} \mathrm{~N}$ range significantly increased with the number of native secondary consumers $(\mathrm{p}=0.012$; Table 2$)$ and non-native primary consumers $(p=0.022$; Table 2$)$. The total isotopic niche size of native species increased with the number of native secondary consumers $(p<0.001$; Table 2$)$ and native predators $(p=0.001$; Table 2$)$. Increased number of nonnative secondary consumers significantly reduced the total isotopic niche size of native species $(p=0.048$; Table 2 and Supplementary material Appendix 3).

\section{Discussion}

Using a unique database on stable isotope values of fish in freshwater ecosystems throughout the world, we first demonstrated the existence of different isotopic structures in communities with non-native fish species compared to communities without non-native fish species. Second, we found that the trophic position of non-native species influenced their effects on the isotopic structure of recipient communities. Additionally, we demonstrated that most of the effects caused by non-native species on the isotopic structure of communities differed between lotic and lentic ecosystems.

In lotic ecosystems such as rivers and streams, and irrespective of species richness, total isotopic niche was significantly larger in communities containing non-native species than in communities without non-native species. No differences in the size of core isotopic niche were observed, indicating that non-native species were mainly located at the edges of the isotopic niche. Concurrently, we found that the increase of the $\delta^{15} \mathrm{~N}$ range was driven by non-native top predators. All together, these findings indicate that, in lotic ecosystems, changes were driven by the addition of nonnative predators at the top of the food chains, lengthening food chain (Eby et al. 2006, Post and Takimoto 2007, Cucherousset et al. 2012b, Walsworth et al. 2013). No effect on the isotopic niche of native species was observed, and this result confirmed the external position of non-native species that did not have a significant compressing effect on native species trophic niche. This last finding is, however, contrasting with the results of Walsworth et al. (2013) that demonstrated a compression of the isotopic niche of native species in invaded desert streams in the United States and further investigations are needed to understand the factors driving the isotopic response of native species.

In lentic ecosystems such as lakes and reservoirs, we found that the effects of the presence of non-native species on total and core isotopic niche size differed and were dependent upon species trophic position. While the total isotopic niche size increased slower with species richness when non-native fish species were present, we found a decrease in the core isotopic niche size, indicating that non-native species were located at the centre (rather than at the edges) of the 
isotopic space of invaded communities. Concurrently, this was associated with a decrease in $\delta^{13} \mathrm{C}$ range driven by the number of non-native secondary consumers that had, overall, a stronger effect than non-native top predators in increasing $\delta^{13} \mathrm{C}$ range. This indicates a modification in the contribution of the basal resources fuelling recipient communities. This could be driven, for instance, by multi-chain omnivory, a process whereby organisms in lentic ecosystems exploit simultaneously resources originating from both pelagic and littoral food chains (Vadeboncoeur et al. 2005). We also found that the number of non-native secondary consumers decreased the total isotopic niche size of native species. This demonstrated a native species' isotopic niche compression which could be caused by a diet shift induced by competition with non-native species (Vander-Zanden et al. 1999). While differences in $\delta^{13} \mathrm{C}$ ranges are primarily driven by differential contributions of the basal resources fuelling a community, they can also be affected by the stable isotope values of basal resources themselves (Hoeinghaus and Zeug 2008). It is therefore of upmost importance to determine whether, by modifying the ecological interactions within communities, non-native species could play a role in the stable isotope values of basal resources through a modification of biochemical processes. Finally, the increase of $\delta^{15} \mathrm{~N}$ range of recipient communities was caused by the presence of non-native primary consumers at the base of the food chain which might increase resource availability for species at higher trophic levels, increasing the maximal trophic position and food chain length in recipient communities, although this remains to be explicitly tested.

Lotic and lentic ecosystems function distinctively. Indeed, lakes are considered as relatively stable ecosystems compared to rivers that are dynamic ecosystems where water and energy flow from upstream to downstream (Horne and Goldman 1994). This was confirmed by the fact that $\delta^{13} \mathrm{C}$ ranges differed significantly between these two types of ecosystems with $\delta^{13} \mathrm{C}$ ranges being significantly larger in lentic ecosystems than in lotic ecosystems (Supplementary material Appendix 2). This result is notably consistent with the differences observed in term of trophic subsidies entering and being consumed in lotic and lentic ecosystems (Gratton and Vander-Zanden 2009, Bartels et al. 2012). We also showed that lotic ecosystems have smaller $\delta^{15} \mathrm{~N}$ range than lentic ecosystems (Supplementary material Appendix 2) and this is consistent with the findings of Vander-Zanden and Fetzer (2007) demonstrating that, at a global scale, the length of food chain was shorter in lotic (i.e. streams, rivers) than in lentic (i.e. lakes, reservoirs) ecosystems. Lotic and lentic ecosystems differed in their responses to the introduction of non-native fish species. Although the number of non-native top predators was the primary agent affecting the isotopic diversity of lotic ecosystems, lentic ecosystems were primarily influenced by non-native secondary consumers and predators (horizontal dimension) and non-native primary consumers (vertical dimension). This might reflect the fact that, at least in our database, lentic ecosystems have more complex isotopic structure (vertical and horizontal variations) than lotic ecosystems (mainly vertical variations), although again this hypothesis remains to be tested. Of importance would be to identify the characteristics (e.g. taxonomic, functional and phylogenetic) of the species that cause different impacts on the isotopic structure of fish communities in lotic and lentic ecosystems.
In conclusion, the present study quantified for the first time how differences in diversity patterns caused by the introduction of non-native species were associated with differences in the isotopic structure of fish communities at a global scale. We demonstrated that this phenomenon was highly ecosystem-dependant and, most importantly, depended on the trophic position of non-native species. The next steps would be to determine if similar responses are observed in other ecosystems (e.g. marine, terrestrial) and to quantify how these changes in trophic diversity of fish communities translate into changes in the entire food web structure and ecosystem functioning and stability (McCann 2000, Folke et al. 2004, Thompson et al. 2012) since biological invasions are a key component of global changes.

Acknowledgements - We are grateful to Julian D. Olden for providing valuable comments to an earlier version of this manuscript that greatly improved it. Funding support was provided by an 'ERG Marie Curie' grant (PERG08-GA-2010-276969) to JC. EDB is part of the 'Laboratoire d'Excellence' (LABEX) entitled TULIP (ANR-10-LABX-41).

\section{References}

Bartels, P. et al. 2012. Reciprocal subsidies between freshwater and terrestrial ecosystems structure consumer resource dynamics. - Ecology 93: 1173-1182.

Blanchet, S. et al. 2010. Non-native species disrupt the worldwide patterns of freshwater fish body size: implications for Bergmann's rule. - Ecol. Lett. 13: 421-431.

Boettiger, C. et al. 2012. rfishbase: exploring, manipulating and visualizing FishBase data from R. - J. Fish Biol. 81: 2030-2039.

Cardinale, B. J. et al. 2006. Effects of biodiversity on the functioning of trophic groups and ecosystems. - Nature 443: 989-992.

Copp, G. H. et al. 2005. To be, or not to be, a non-native freshwater fish? - J. Appl. Ichthyol. 21: 242-262.

Crawley, M. 2012. The R book. - Wiley.

Cucherousset, J. and Olden, J. D. 2011. Ecological impacts of non-native freshwater fishes. - Fisheries 36: 215-230.

Cucherousset, J. et al. 2012a. Using stable isotope analyses to determine the ecological effects of non-native fishes. - Fish. Manage. Ecol. 19: 111-119.

Cucherousset, J. et al. 2012b. Non-native species promote trophic dispersion of food webs. - Front. Ecol. Environ. 10: 406-408.

Duffy, J. E. et al. 2007. The functional role of biodiversity in ecosystems: incorporating trophic complexity. - Ecol. Lett. 10: 522-538.

Eby, L. A. et al. 2006. Effects of stocking-up freshwater food webs. - Trends Ecol. Evol. 21: 576-584.

Folke, C. et al. 2004. Regime shifts, resilience, and biodiversity in ecosystem management. - Annu. Rev. Ecol. Evol. Syst. 35: 557-581.

Froese, R. and Pauly, D. 2013. FishBase. $-<$ www.fishbase.org $>$.

Fry, B. 2006. Stable isotope ecology. - Springer.

Gratton, C. and Vander-Zanden, M. J. 2009. Flux of aquatic insect productivity to land: comparison of lentic and lotic ecosystems. - Ecology 90: 2689-2699.

Hoeinghaus, D. J. and Zeug, S. C. 2008. Can stable isotope ratios provide for community-wide measures of trophic diversity? - Ecology 89: 2353-2357.

Horne, A. and Goldman, C. R. 1994. Limnology. - McGraw-Hill.

Jackson, A. L. et al. 2011. Comparing isotopic niche widths among and within communities: SIBER - stable isotope Bayesian ellipses in R. - J. Anim. Ecol. 80: 595-602.

Layman, C. A. et al. 2007. Can stable isotope ratios provide for community-wide measures of trophic structure? - Ecology 88: 42-48. 
Lehner, B. et al. 2006. HydroSHEDS technical documentation. $<$ http://hydrosheds.cr.usgs.gov/webappcontent/HydroSHEDS_TechDoc_v10.pdf 1-27>.

McCann, K. S. 2000. The diversity-stability debate. - Nature 405: 228-233.

Pinheiro, J. C. et al. 2013. nlme: linear and nonlinear mixed effects models. - R package ver. 3.1-113, R Development Core Team.

Post, D. M. and Takimoto, G. 2007. Proximate structural mechanisms for variation in food-chain length. - Oikos 116: 775-782.

Rooney, N. and McCann, K. S. 2012. Integrating food web diversity, structure and stability. - Trends Ecol. Evol. 27: 40-46.

Schmidt, S. N. et al. 2011. Historical and contemporary trophic niche partitioning among Laurentian Great Lakes coregonines. - Ecol. Appl. 21: 888-896.

Supplementary material (Appendix ECOG-01348 at $<$ www.ecography.org/readers/appendix $>$ ). Appendix 1-3.
Thompson, R. M. et al. 2012. Food webs: reconciling the structure and function of biodiversity. - Trends Ecol. Evol. 27: 689-697.

Vadeboncoeur, Y. et al. 2005. Effects of multi-chain omnivory on the strength of trophic control in lakes. - Ecosystems 8: 682-693.

Vander-Zanden, M. J. and Fetzer, W. W. 2007. Global patterns of aquatic food chain length. - Oikos 116: 1378-1388.

Vander-Zanden, M. J. et al. 1999. Stable isotope evidence for the food web consequences of species invasions in lakes. - Nature 401: 464-467.

Walsworth, T. E. et al. 2013. Longer food chains and crowded niche space: effects of multiple invaders on desert stream food web structure. - Ecol. Freshw. Fish 22: 439-452. 